\title{
The Aesthetics and Emotions of Religious Belonging: Examples from the Buddhist World
}

\author{
Erica Baffelli | ORCID: 0000-0003-3236-8814 \\ Department of Modern Languages and Cultures, \\ The University of Manchester, Manchester, UK \\ erica.baffelli@manchester.ac.uk \\ Jane Caple | ORCID: 0000-0002-5104-1174 \\ Independent scholar, Mytholmroyd, UK \\ janecaple74@gmail.com \\ Levi McLaughlin | ORCID: 0000-0001-9590-0631 \\ Department of Philosophy and Religious Studies, \\ North Carolina State University, Raleigh NC, USA \\ lmclaug2@ncsu.edu
}

\author{
Frederik Schröer | ORCID: 0000-0002-2106-7816 \\ Center for the History of Emotions, Max Planck Institute \\ for Human Development, Berlin, Germany \\ schroeer@mpib-berlin.mpg.de
}

\begin{abstract}
The articles in this special issue illuminate the importance of aesthetics, affect, and emotion in the formation of religious communities through examples from the Buddhist world. This introduction reads across the contributors' findings from different regions (China, India, Japan, and Tibet) and eras (from the 17 th to the 21 st centuries) to highlight common themes. It discusses how Buddhist communities can take shape around feelings of togetherness, distance, and absence, how bonds are forged and broken through spectacular and quotidian aesthetic forms, and how aesthetic and emotional practices intersect with doctrinal interpretations, gender, ethnicity, and social distinction to shape the moral politics of religious belonging. We reflect on how this special issue complicates the idea of Buddhist belonging through its focus on
\end{abstract}


oft-overlooked practices and practitioners. We also discuss the insights that our studies of Asian Buddhist communities offer to the broader study of religious belonging.

\section{Keywords}

aesthetics - Buddhism - belonging - emotions

Aesthetic forms and emotional practices central to community formation and religious belonging have remained under-researched in the study of Buddhism. To address these gaps, this special issue synthesizes findings from a range of Buddhist and Buddhism-related contexts in China, India, Japan, and Tibet. It traces the aesthetics and emotions of belonging among a wide variety of Buddhist actors, young and old, from across Asia, including shopkeepers, musicians, students, homemakers, farmers, urban professionals, and visiting dharma practitioners from around the globe. It journeys beyond the human realm to engage with apotheosized visionaries and Buddhist hierarchs. Overall, the articles assembled here pursue the question of how aesthetic configurations influence ways Buddhists relate to themselves and their communities. We ask what can be learned about ongoing Buddhist belonging and community formation from analyses of how aesthetic forms - rituals, scriptures, images, accounts of dreams and visions, meals, music, and more - elicit affects and emotions. Finally, by focusing on aesthetics and emotions, we problematize understandings of what does or does not count as Buddhism.

One concern shared by the subjects who appear in these articles is which activities, objects, bodies, and emotions do or do not count as or feel authentically "Buddhist." What and who should and should not belong to their communities? People who appear in these studies articulate a moral politics of belonging through quotidian concerns, such as how food is prepared and consumed (Kolata and Gillson 2021), how one appreciates music (McLaughlin 2021), the emotional style of interactions between community members (Caple 2021), or if one has the innate sensibility to feel whether or not a Buddhist commodity for sale in a local market is "true" (Brox 2021). The emphasis throughout is less a matter of determining static boundaries around what Buddhism is than analyzing how it is done. Belonging hinges on how Buddhism is felt, sensed, and produced through aesthetic forms and emotional practices that enact joy, hope, suffering, faith, doubt, and pain. These feelings are interdependent with doctrines, liturgies, and other institutionally mandated conventions. 
The specific cases we examine extend from socio-historically embedded "traditional" Buddhist communities (Brox 2021; Caple 2021; Kolata and Gillson 2021) and emerging or expanding lineage traditions (Townsend 2021b; Williams-Oerberg 2021) to stigma-laden "new religions" (Baffelli and Schröer 2021; McLaughlin 2021). The authors treat each case as a carefully contextualized site within which to explore our shared questions about how it feels the way it does to belong to a Buddhist community and how these communities' constituent aesthetic practices guide their participants' understandings of themselves. Studying Buddhist communities in situ means taking seriously not only founders and dharma heirs but also the on-the-ground and the everyday, including numerous actors and aspects of Buddhism that tend to be marginalized in doctrine- and institution-centered research. Focusing our attention beyond conventional frameworks reveals the centrality of aesthetic practices, affects, and emotions in the ongoing formation of Buddhist communities. Attention to aesthetic practices reveals reasons for connections and divisions between and within Buddhist communities and uncovers how affective and emotional bonds shape adherents' material practices and existential concerns, such as individual and collective temporalities, economic systems, political ideologies, notions of authenticity, and visions of transcendence.

This issue takes the perspective of aesthetics as aisthesis, or the process of sentient sense perception that encompasses the entire sensoria, the actions that stimulate it, and how sensations are apprehended by subjects. This is what Alexandra Grieser and Jay Johnston refer to as "an analytic strand" of aesthetics in distinction to "a normative strand" that attends to aesthetics in the narrower sense of "what is, or should be seen as beautiful" (Grieser and Johnston 2017: 8). The authors situate aesthetics and emotions that manifest Buddhism in their analyses as intersubjective practices. The articles thus share a strongly praxeological approach that is still relatively new in the study of aesthetics and emotions (e.g., Meyer 2009; Scheer 2012; Schaefer 2015; Böhme 2017; Baader 2019). As they explore contrasting geographical, historical, social, and political contexts of Buddhist belonging, the contributors employ a variety of methodological and theoretical tools to highlight intersections with economics, gender, social class, ethnicity, and temporality.

By paying attention to the formulation of Buddhist ideas and practices of belonging within institutions and in vernacular contexts across Asia through text-based and ethnographic research, these articles generate novel concepts and provide new insights into aesthetic and emotional dimensions of religious belonging and community-building that apply beyond Buddhist contexts. They also contribute to the problematization of "Buddhism" as a category. The contributors necessarily rely on their interlocutors' self-descriptions as 
Buddhists and eschew prescriptive definitions of Buddhism, or religion, based on doctrine or institutional authority. In keeping with recent studies that adopt a similar approach (Lewis 2014; Samuels et al. 2016; Rowe 2017; Starling 2019), they stress the importance of practitioners' voices and understandings gleaned from fieldwork, noncanonical documents, and other sources that demonstrate Buddhist community-building in the terms employed by their participants. Perspectives afforded by these sources reveal that aesthetic forms and their attendant sensorial and emotional practices comprise a nexus within which the phenomenon labeled "Buddhism" and affective belonging are coconstituted.

\section{$1 \quad$ Refiguring Aesthetics, Emotions, and Temporalities}

This special issue is the product of an annual seminar titled "The Aesthetics of Religious Belonging," which was hosted by the University of Copenhagen and The University of Manchester. ${ }^{1}$ The seminar brought together largely earlycareer researchers in Asian Studies based in the USA and Europe who focus on early modern to contemporary Buddhism. At our meetings, we shared the fruits of our historical and ethnographic research as we discussed work to date on affect, emotion, and material religion. From the outset, the intent of the workshop was to expand from this research purview while we built on previous findings. The articles in this issue draw on theories of affect and emotion by looking at the role of sensational forms and aesthetics of persuasion in creating modalities of belonging (Meyer 2009, 2010, 2012), the performative aspects of charisma and resulting interrelational connections (Csordas 1997), how affective values and economies create boundaries between the individual and the social (Ahmed 2004, 2015), the role of feelings in community creation (Pernau 2017), emotional styles developed through specific patterns (Gammerl 2012), and how religious values moralize emotional practices (Desjarlais 1992; Cassaniti 2014).

While affect and emotion studies literature informs this issue, the authors recognize that this is a field that tends to take Euro-American scholarship and

1 This seminar was initiated by Elizabeth Williams-Oerberg and Levi McLaughlin. It has been cofunded by the Danish Council for Independent Research | Humanities and the European Union's Horizon 2020 research and innovation programme under the Marie Skłodowska-Curie grant agreement No. 747673 (2018); and the University of Manchester School of Arts, Languages and Cultures (2019). 
religious experiences as a tacitly agreed-upon standard frame (Pernau 2021). The articles assembled here extend beyond existing scholarship through their focus on aesthetics and Buddhism in Asia. Each shapes its approach and selects its theoretical tools to fit the individual context, since analytical lenses such as affect, emotions, or feelings each generate their own lines of inquiry (Boddice 2018; Schaefer 2019). The broader framework of aesthetics, however, means that all of the studies integrate, to varying degrees, a spectrum that ranges from visceral bodily affects to highly refined emotional cultures. The issue uses this diversity in approaches and case studies to destabilize and provincialize concepts such as belonging, authenticity, and temporality. We follow actors who negotiate the authenticity of religious objects through their "aesthetic habitus" (Brox 2021), who sustain belonging through "feeling apart" (Caple 2021), or whose communities center on emotions that relate simultaneously to multiple temporalities (Baffelli and Schröer 2021). Our actors are found embedded in complex aesthetic formations of spectacle (Williams-Oerberg 2021), foodways (Kolata and Gillson 2021), musical practice (McLaughlin 2021), and textual narrative (Townsend 2021b). The works collected here break with popular perceptions of Buddhism as emotionally austere (Cassaniti 2014: 28o-281). Each considers a dynamic spectrum of affects and emotions that enact and are deeply influenced by Buddhism while they generate theoretical propositions that can be applied to non-Buddhist frameworks.

At the same time, the authors contribute to ongoing discussions about Buddhist communities, including studies of aesthetics and Buddhist authority (McDaniel 2016; Castiglioni 2019) and Buddhist moralities (Euron 2017; Kidd 2017). Other scholars have explored and cross-culturally compared individual emotions in Buddhism (Brekke 1999; Dreyfus 2002; Gowans 2010; Horton et al. 2012; Makransky 2012) or have reflected on theories of emotions in Buddhist epistemologies (Harvey 2013; Peacock and Batchelor 2018). Studies of Buddhist monastic communities have highlighted the importance of aesthetic sensibilities (Samuels 2010; Townsend 2021a) and intimate connections (Starkey 2019) in creating communities and maintaining bonds between members, as well as the ambiguous role of emotions in Buddhist monastic hierarchies and disciplinary practices (Dreyfus 2003; Lempert 2012).

As a starting point, the authors take aesthetics to be at the heart of religious belonging and not as a secondary effect of community or a characteristic peculiar to singular practices, contexts, or forms of community. As is also reflected in the broader aesthetics of religion field, the actors, practices, and contexts presented here show that the importance of paying attention to "aesthetics and the sensory" is not particular to studies of "the present reconfiguration 
of religion in a market regime," as François Gauthier suggests (Gauthier 2017: 452). ${ }^{2}$ While six of the seven articles focus on 2oth- and 21st-century Buddhists, Dominque Townsend's analysis of Tibetan Buddhist Treasure (gter $\mathrm{ma}$ ) literature, which took shape from the 8th century, highlights diachronic continuities in the emotives generating belonging within Treasure communities up to the present.

Key to understanding Buddhist aesthetics is close attention to content and how it is formulated. This requires explanations of the work that goes into constructing aesthetic forms that generate affect-driven community belonging. While Elizabeth Williams-Oerberg's contribution, for example, touches upon what has elsewhere been framed as the aestheticization of religion - its "spectacularization" and "transformation in entertainment" (da Silva Moreira 2018) - she also details the unspectacular labor that is required to produce aesthetic effects and points to Buddhist actors' uneven success in creating a unified response to events intended to elicit a transformative impact. Paulina Kolata and Gwendolyn Gillson look at the careful crafting of meals to discuss how a "food literacy" polished through refining skills for preparing, presenting, serving, and enjoying culinary performances fosters a sense of belonging among Buddhist women. Levi McLaughlin delves into musicological detail to explain how members of the Japanese lay Buddhist group Soka Gakkai adapted a modern Japanese obsession with Ludwig van Beethoven to treat performances of the composer's works as a means of articulating Buddhist authenticity.

Another dimension, highlighted by Erica Baffelli and Frederik Schröer, is the importance of time in the study of religion's aesthetic and emotional dimensions. They show how former adherents of the disbanded Japanese apocalyptic sect Aum Shinrikyō and diasporic Tibetans in the 2oth century formulated their communities in relation to incommensurate and multiple pasts, presents, and futures. Jane Caple also picks up on temporality in her discussion of how past rupture and precarious presents and futures destabilize the apparently routine and habituated emotional patterns and practices central to Buddhist monastic-lay communities in contemporary Tibet. The article by Baffelli and Schröer and the contribution by Townsend make clear that Buddhist epistemologies complicate linear understandings of temporality and causation. Time instead emerges as a complex weave of interconnections that actors negotiate by means of aesthetics and emotions. Interconnection is at the heart of

2 For an overview of the history of the aesthetics of religion field, see Grieser and Johnston 2017: 16-19. Although Gauthier's (2017) chapter was published in their edited volume, other chapters, including the editors' introduction (Grieser and Johnston 2017), do not take such a narrow view. See also Koch and Wilkens 2019; Johannsen, Kirsch, and Kreinath 2020. 
Buddhist concepts of interdependence and rebirth, and the very worldly and social effects that these produce on the ground, as Williams-Oerberg's theory of "connectionwork" explores. These and the other articles call into question how time should be assessed if we place aesthetics at the center of the picture.

\section{Buddhist Belonging: From the Everyday to the Extraordinary}

These articles demonstrate a need to interrogate the category "belonging" by situating actors' lives and practices in their historical, political, and social frameworks. This approach complicates straightforward notions of "Buddhist belonging" as it decenters and enriches the concept of belonging by infusing its theoretical framing with fresh insights from oft-overlooked milieus. As Townsend points out (2021b), scholars working on Buddhism in Asia have tended to focus on the aesthetics of religious authority (e.g., Ji 2008; Huang 2009; Smyer Yü 2012; Turek 2017; Castiglioni 2019). By including a fuller range of those who formulate and practice religious belonging rather than prioritizing powerholders, these articles explore how humble adherents and leaders alike make, and make sense of, their connections to one another, to lineages, and to the category "Buddhism" itself.

An important dimension of belonging highlighted by the articles is everyday affective labor, central to the ongoing formation of Buddhist communities. This includes the creative use of aesthetic forms by established authorities to "strengthen and expand religious community" (Williams-Oerberg 2021) or by visionaries engaging in an aesthetics of persuasion oriented as much toward themselves as others (Townsend 2021b). It can also include the care taken in the preparation of a dish of rice and beans (Kolata and Gillson 2021); the dedication of working through basic exercises to perfect instrumental technique (McLaughlin 2021); the sorting of sounds, smells, and sights as one shops in a market (Brox 2021); or even the act of rising to one's feet when someone enters a room (Caple 2021). The upheaval of extraordinary events can precipitate the formation of new communities and connections (Baffelli and Schröer 2021; Townsend 2021b; Williams-Oerberg 2021). But bonds between members are sustained and shaped through everyday aesthetic forms and emotional practices, as well as through their refusal (Caple 2021; Kolata and Gillson 2021; Williams-Oerberg 2021) or appropriation (Brox 2021). This is so even if, as McLaughlin indicates, changing institutional dynamics can render precisely what it is that members belong to less clear.

Attention to hierarchies, cleavages, and contestations within Buddhist communities also sharpens understandings of how actors negotiate belonging. 
Williams-Oerberg outlines failures to breach national and socioeconomic gaps between participants in a mass Buddhist spectacle designed to foster devotion and deepen adherents' solidarity. Kolata and Gillson shed light on the mismatch between differing sorts of Buddhist food-based literacy among adherents from contrasting social groups and sectarian traditions, while Townsend points to the challenges that Tibetan Treasure revealers have faced from monastic authorities when negotiating their belonging as visionaries. Baffelli and Schröer show how "feeling together" can emerge from members' felt lack of synchronicity with the wider society in which they find themselves (see also Brox 2021), while Caple highlights the importance of feelings of distance between members in monastic-lay community formation. As she emphasizes, people not only belong to, in, or with religious communities, but must negotiate their belonging as particular kinds of community members and in relation to attendant aesthetic norms and feeling rules. Moreover, how belonging is sensed, experienced, and practiced is entangled with other categories of social being, such as ethnicity or nationality (Baffelli and Schröer 2021; Brox 2021; Williams-Oerberg 2021), gender (Kolata and Gillson 2021), and cultural distinction (McLaughlin 2021). The articles push us to include a range of intersectional components in our analyses of how Buddhist belonging, and religious belonging more generally, is practiced. While attention to the everyday provides much of the data presented in this issue, large-scale spectacles and the activities of Buddhist elites also receive due attention.

Aesthetics and emotions necessarily produce practices of inclusion and exclusion. Trine Brox reminds us that the concept of belonging carries an oblique normative valuation: to belong is better than to not belong, even if belonging accrues costs. Her discussion of the aesthetics of in/authenticity in an urban Chinese marketplace resonates with observations made by Baffelli and Schröer, McLaughlin, and Williams-Oerberg, who demonstrate that analyzing belonging necessitates attention to non-belonging, in terms of actors' relations to external society and to their communities. As Caple highlights, belonging involves varying and shifting degrees of affinity that can be measured in actors' micro-level engagements.

There are always tensions inherent within even the most routine or modest practices of belonging, for so much is at stake. Aesthetic forms and emotional practices are central to the control and expansion of politically powerful institutions that amass material wealth (Williams-Oerberg 2021); the authority to establish new dharma lineages and authenticate newly discovered teachings (Townsend 2021b); the right to the last word on ritual conduct or doctrinal interpretation (Kolata and Gillson 2021; McLaughlin 2021); or a community's very survival (Baffelli and Schröer 2021; Brox 2021; Caple 2021). 
While there is no reliable answer to the question "what counts as Buddhist?", the authors were inspired to collaborate because they observe important continuities and informative differences across the Buddhist and Buddhism-proximate phenomena they research. The contributions shed light on a diverse tableau of issues that are quotidian and exceptional, vernacular and vital to debates in the study of religion. Sounds, smells, tastes, appearances, looking and looking away, presence and absence, dreamscapes and kitsch, the authentic and the inauthentic - the list of aesthetics and their effects is as extensive as the category is productive. By training our lenses on a broad range of actors and contexts, the contributions collected here reveal details that complicate existing theoretical debates in the study of religion and beyond.

This brings us to the individual contributions. By shifting the focus from sectarian or geographical understandings of Buddhist communities to the aesthetics and emotions of belonging, this collection consciously avoids prevailing divisions such as "new" versus "traditional" Buddhist groups, or "Japanese" versus "Tibetan" Buddhism. Some of the articles place greater emphasis on emotion (Baffelli and Schröer, Townsend), affect (Kolata and Gillson, Williams-Oerberg), or feeling (Brox, Caple); some focus on micro-practices (Caple, Kolata and Gillson, McLaughlin); and some foreground the aesthetics of persuasion (Brox, Townsend, Williams-Oerberg). The aim of this introduction has been to highlight the themes that cut across them. To inspire further conversation about how these studies speak to one another, we have grouped the articles in this issue into three thematic clusters. However, we suggest that readers may discover fresh insights by reading them in an order of their own choosing.

\subsection{Emotion, Temporalities, and Community Formation}

We start with Erica Baffelli and Frederik Schröer, who employ the analytical concept of "feeling communities" to theorize the role of emotions in the creation of religious belonging. As their theory-focused article reveals, studying belonging means following the efficacy of emotions, their intersubjective circulation and contestation, and their temporal relations to different pasts, presents, and futures. Drawing on two contrasting geographical and historical contexts and groups of actors, namely members of the early Tibetan diaspora in India (1959-1979) and former members of Aum Shinrikyō in Japan, the authors uncover how an absence - in the form of a homeland after forced migration, or of a religious community after its traumatic disruption - can be a productive condition in the creation of communities as feeling communities, or as "communities of absence." 
While Baffelli and Schröer focus on absence as formative of belonging, Jane Caple emphasizes the importance of relations of distance between community members. In her contribution, which focuses on monastic-lay communities in northeast Tibet (Amdo), she explores everyday practices of reverence and faith that materialize community by creating feelings of otherness as well as togetherness. By examining the stakes of apparently routine relations of belonging between laity and monks in relation to violent and utopian pasts and precarious presents, she emphasizes the felt contingency of even highly institutionalized religious communities. She also analyzes how religious belonging is experienced and sensed differently depending on who one belongs $a s$, arguing that practices of "feeling apart" and their refusal can be central to both individual negotiations of religious belonging and the dynamic process of ongoing community formation.

\subsection{Aesthetics of Persuasion and Authenticity}

Elizabeth Williams-Oerberg takes us to Ladakh in northern India and the spectacular Naropa Festival 2016, which centered on the Naro Gyen Druk ritual, an event that pronounced the twelfth Gyalwang Drukpa as dharma heir and transcendent leader for his assembled devotees. She develops the concept of "connectionwork" to identify how drelwa ('brel-ba), or karmic bonds, either fuse or fail depending on the success of the labor undertaken by actors who participate in rituals intended to forge these links. Her analyses of the mismatched expectations of international pilgrims and Ladakhi Buddhists, in particular the local youth to whom the spectacular 2016 festival was planned to appeal, demonstrate significant contrasts in affective responses to the same rituals and the agential role participants play in charismatic performances. In other words, the article demonstrates the work required for connectionwork.

Dominique Townsend's article offers a historical investigation into the ongoing impact on Buddhist community formation of lineage claims, ritual authority, institutional leadership, and literary aesthetics by taking into account the narrative accounts of 17 th- and 18th-century Tibetan visionaries. She considers ways that exponents of the Tibetan Buddhist Treasure tradition infused their vivid descriptions of received visions with richly imagined tales suffused with sensorial delights, as well as expressions of doubt. Townsend analyses how these accounts cultivated a sense of belonging in both their authors and readers by providing them with means of navigating through doubt to assert belonging to lineages that rooted their authority in visions that articulated persuasive aesthetic experiences.

Trine Brox shifts our attention to the moral politics of ethnoreligious belonging as she takes the reader on a stroll through the Tibetan market of 
Wuhouci in the Chinese metropolis of Chengdu, which she frames as a "contact zone" where ethnic Tibetans and Han Chinese interact as shop owners and customers. Her analysis shows how people negotiate religious and ethnic belonging via an everyday "aesthetics of authenticity" as they assess sights, sounds, smells, and bodies in the bustling market. By moving away from the explicitly religious spaces of monasteries and temples, the article identifies how understandings of "real" Buddhism are articulated in daily life. This articulation involves complex navigations of religious belonging, which connect to larger narratives of religious revival, commodification, and the demise of ethno-religious community.

\subsection{Micropractices of Belonging}

Paulina Kolata and Gwendolyn Gillson focus on the aesthetic practices of female Buddhist practitioners in contemporary Japan, providing diverse contexts and perspectives on practices concerning food and how this clearly gendered form of religious expertise generates belonging and articulates its boundaries. Here, too, the reader gains new insights into the understudied lives of nonelite actors, as well as the specific gendered and aesthetic practices through which they negotiate belonging. By discussing how food is prepared and experienced, this article highlights the importance of micropractices and their aesthetics. Conceptualizing food literacy as a form of "gendered currency," they unravel how gender, social status, and other power dynamics formulate practices of self-cultivation, exclusion, and inclusion. The authors attend to the gendered and economic contexts for the circulation of material objects and subjective senses of religious belonging.

In Levi McLaughlin's article we turn to music as the central focus. He provides observations derived from playing violin in Japan with musicians in the lay Nichiren Buddhist organization Soka Gakkai. The article discusses how one group of Gakkai musicians conflated European aesthetics with Buddhist teachings in the course of playing Beethoven as a key component of their practice. This study identifies what practitioners count as authentically Buddhist by focusing on how members of a Soka Gakkai symphony orchestra articulated discipleship through pedagogical instruction. By situating the musicians' training within the larger framework of Soka Gakkai's tumultuous development, the article provides a case study of ways adherents necessarily confront the dilemma of "to what do we belong?" when they contend with leadership disputes, battles over orthodoxy and orthopraxy, and generational shifts. It also asserts that we must be prepared to consider ways aesthetic forms create religion, rather than the reverse. 
In sum, the articles in this collection demonstrate exciting potential for investigating the role of aesthetics and emotion in individual and localized negotiations of religious belonging and the formation of religious communities. As case studies, they contribute new perspectives on Buddhist practices and belonging, but their findings also apply beyond their specific contexts to investigations of how religious communities take shape and how aesthetic forms and emotional practices generate, and sometimes break, bonds between their participants.

\section{Acknowledgments}

We would like to thank the other members of the research group "The Aesthetics of Religious Belonging," Trine Brox, Gwendolyn Gillson, Paulina Kolata, Dominique Townsend, and Elizabeth Williams-Oerberg for the discussions, comments, and constructive criticism that contributed to this introduction, and for sticking to deadlines despite the continuous disruptions caused by the CoviD-19 pandemic. Thank you also to Numen editors Laura Feldt and Ülo Valk for their careful reading and insightful comments.

\section{References}

Ahmed, Sara. 2004. “Affective Economies." Social Text 22(2): 117-139. DoI:10.1215/ o1642472-22-2_79-117.

Ahmed, Sara. 2015. The Cultural Politics of Emotion. 2nd ed. Durham, NC: Duke University Press.

Baader, Hannah. 2019. "Epilogue. Aesthetic Practices and Transcultural Art Histories | Epílogo. Prácticas Estéticas E Historias Del Arte Transculturales.” In Sanja Savkić (ed.), Indigenous Visual Cultures and Aesthetic Practices, Berlin: Gebr. Mann, 427-431.

Baffelli, Erica, and Frederik Schröer. 2021. "Communities of Absence: Emotions, Time, and Buddhism in the Creation of Belonging." Numen 68(5-6): 436-462. DOI:10.1163/15685276-12341635.

Boddice, Rob. 2018. The History of Emotions. Manchester: Manchester University Press.

Böhme, Gernot. 2017. The Aesthetics of Atmospheres. Jean-Paul Thibaud (ed.). London: Routledge.

Brekke, Torkel. 1999. "The Role of Fear in Indian Religious Thought with Special Reference to Buddhism." Journal of Indian Philosophy 27(5): 439-467.

Brox, Trine. 2021. "The Aesthetics of In/Authenticity: Buddhism, Commodification, and Ethnoreligious Belonging in a Sino-Tibetan Contact Zone." Numen 68(5-6): 540-566. DOI:10.1163/15685276-12341639. 
Caple, Jane. 2021. "Feeling Apart: Relations of Belonging in Tibetan Buddhist LayMonastic Communities." Numen 68(5-6): 463-487. Dor:10.1163/15685276-12341636.

Cassaniti,Julia L. 2014. "Moralizing Emotion:A Breakdown in Thailand." Anthropological Theory 14(3): 280-30o. DoI:10.1177/1463499614534551.

Castiglioni, Andrea. 2019. "Devotion in Flesh and Bone: The Mummified Corpses of Mount Yudono Ascetics in Edo-Period Japan." Asian Ethnology 78(1): 25-52.

Csordas, Thomas J. 1997. Language, Charisma, and Creativity: The Ritual Life of a Religious Movement. Berkeley: University of California Press.

da Silva Moreira, Alberto. 2018. "The Aestheticization of Religion in Brazil (and Probably Elsewhere)." International Journal of Latin American Religions 2: 125-141. DOI:10.1007/s416o3-018-0036-7.

Desjarlais, Robert R. 1992. Body and Emotion: The Aesthetics of Illness and Healing in the Nepal Himalayas. Philadelphia: University of Pennsylvania Press.

Dreyfus, Georges. 2002. "Is Compassion an Emotion? A Cross-Cultural Exploration of Mental Typologies." In Richard J. Davidson and Anne Harrington (eds.), Visions of Compassion: Western Scientists and Tibetan Buddhists Examine Human Nature, Oxford: Oxford University Press, 31-45.

Dreyfus, Georges. 2003. The Sound of Two Hands Clapping: The Education of a Tibetan Buddhist Monk. Berkeley: University of California Press.

Euron, Paolo. 2017. "Beauty and Aesthetic Experience in Theravāda Buddhism." Contemporary Buddhism 18(2): 305-320. DoI:10.1080/14639947.2017.1386415.

Gammerl, Benno. 2012. "Emotional Styles: Concepts and Challenges." Rethinking History 16(2): 161-175. DOI:10.1080/13642529.2012.681189.

Gauthier, François. 2017. "Consumer Culture and the Sensory Remodelling of Religion.” In Alexandra K. Grieser and Jay Johnston (eds.), Aesthetics of Religion: A Connective Concept, Berlin: De Gruyter, 447-456.

Gowans, Christopher W. 2010. "Medical Analogies in Buddhist and Hellenistic Thought: Tranquillity and Anger." In Jonardon Ganeri and Clare Carlisle (eds.), Philosophy as Therapeia, (Royal Institute of Philosophy Supplements), Cambridge: Cambridge University Press, 11-34.

Grieser, Alexandra K., and Jay Johnston. 2017. "What is an Aesthetics of Religion? From the Senses to Meaning - and Back Again." In Alexandra K. Grieser and Jay Johnston (eds.), Aesthetics of Religion: A Connective Concept, Berlin: De Gruyter, 1-49.

Harvey, Peter. 2013. "Emotions in Buddhism." In Douglas J. Davies and Nathaniel A. Warne (eds.), Emotions and Religious Dynamics, Farnham: Ashgate, 47-62.

Horton, Randall, Stephen K. Rice, Nicole Leeper Piquero, and Alex R. Piquero. 2012. "On the Variability of Anger Cross-Culturally: An Assessment of General Strain Theory's Primary Mediator." Deviant Behavior 33(4): 26o-281. DoI:10.108o/o163962 5.2011 .573415 .

Huang, C. Julia. 2009. Charisma and Compassion: Cheng Yen and the Buddhist Tzu Chi Movement. Cambridge, MA: Harvard University Press. 
Ji Zhe. 2008. "Expectation, Affection and Responsibility: The Charismatic Journey of a New Buddhist Group in Taiwan." Nova Religio: The Journal of Alternative and Emergent Religions 12(2): 48-68. DOI:10.1525/nr.2008.12.2.48.

Johannsen, Dirk, Anja Kirsh, and Jens Kreinath (eds.). 2020. Narrative Cultures and the Aesthetics of Religion. Leiden: Brill.

Kidd, Ian James. 2017. "Beautiful Bodhisattvas: The Aesthetics of Spiritual Exemplarity." Contemporary Buddhism 18(2): 331-345. DOI:10.1080/14639947.2017.1386417.

Koch, Anne, and Katharina Wilkens (eds.). 2019. The Bloomsbury Handbook of the Cultural and Cognitive Aesthetics of Religion. London: Bloomsbury Academic.

Kolata, Paulina, and Gwendolyn Gillson. 2021. "Feasting with Buddhist Women: Food Literacy in Religious Belonging." Numen 68(5-6): 567-592. DoI:10.1163/ 15685276-12341640.

Lempert, Michael. 2012. Discipline \& Debate: The Language of Violence in a Tibetan Buddhist Monastery. Berkeley: University of California Press.

Lewis, Todd. 2014. Buddhists: Understanding Buddhism through the Lives of Practitioners. Chichester: Wiley.

Makransky, John. 2012. “Compassion in Buddhist Psychology." In Christopher K. Germer and Ronald D. Siegel (eds.), Compassion and Wisdom in Psychotherapy, New York: Guilford Press.

McDaniel, Justin. 2016. Architects of Buddhist Leisure: Socially Disengaged Buddhism in Asia's Museums, Monuments, and Amusement Parks. Honolulu: University of Hawai'i Press.

McLaughlin, Levi. 2021. "Beethoven and Buddhism in a Japanese Religion: Culture as Cultivation in Soka Gakkai." Numen 68(5-6): 593-618. DoI:10.1163/1568527612341641.

Meyer, Birgit. 2008. "Religious Sensations: Why Media, Aesthetics and Power Matter in the Study of Contemporary Religion." In Hent de Vries (ed.), Religion: Beyond a Concept, New York: Fordham University Press, 704-723.

Meyer, Birgit. 20o9. "Introduction: From Imagined Communities to Aesthetic Formations: Religious Mediations, Sensational Forms, and Styles of Binding." In Birgit Meyer (ed.), Aesthetic Formations: Media, Religion, and the Senses, New York: Palgrave Macmillan, 1-28. DoI:10.1057/9780230623248_1.

Meyer, Birgit. 2010. "Aesthetics of Persuasion: Global Christianity and Pentecostalism's Sensational Forms." South Atlantic Quarterly 109(4): 741-763. DOI:10.1215/ oo382876-2010-015.

Meyer, Birgit. 2012. Mediation and the Genesis of Presence: Towards a Material Approach to Religion. Universiteit Utrecht: Faculteit Geesteswetenschappen.

Peacock, John, and Martine Batchelor. 2018. "Editorial: Vedanā: What Is in a 'Feeling?"” Contemporary Buddhism 19(1): 1-6. DoI:10.108o/14639947.2018.1450966. 
Pernau, Margrit. 2017. "Feeling Communities: Introduction." The Indian Economic \& Social History Review 54(1): 1-20. DoI:10.1177/oo19464616683477.

Pernau, Margrit. 2021. "Introduction: Studying Emotions in South Asia." South Asian History and Culture 12(2):1-18. DoI:10.108o/19472498.2021.1878788.

Rowe, Mark Michael. 2017. "Charting Known Territory: Female Buddhist Priests." Japanese Journal of Religious Studies 44(1): 75-101. DOI:10.18874/jjrs.44.1.2017.75-101. Samuels, Jeffery. 2010. Attracting the Heart: Social Relations and the Aesthetics of Emotion in Sri Lankan Monastic Culture. Honolulu: University of Hawai' i Press.

Samuels, Jeffrey, Justin Thomas McDaniel, and Mark Michael Rowe (eds). 2016. Figures of Buddhist Modernity in Asia. Honolulu: University of Hawai'i Press.

Schaefer, Donovan O. 2015. Religious Affects: Animality, Evolution, and Power. Durham, NC: Duke University Press.

Schaefer, Donovan O. 2019. The Evolution of Affect Theory. Cambridge: Cambridge University Press.

Scheer, Monique. 2012. "Are Emotions a Kind of Practice (and is That What Makes Them Have a History?): A Bourdieuian Approach to Understanding Emotion." History and Theory 51: 193-220. DOI:10.1111/j.1468-2303.2012.00621.x.

Smyer Yü, Dan. 2012. The Spread of Tibetan Buddhism in China: Charisma, Money, Enlightenment. London: Routledge.

Starkey, Caroline. 2019. Women in British Buddhism: Commitment, Connection, Community. London: Routledge.

Starling, Jessica. 2019. Guardians of the Buddha's Home: Domestic Religion in Contemporary Jōdo Shinshū. Honolulu: University of Hawai`i Press.

Townsend, Dominique. 2021a. A Buddhist Sensibility: Aesthetic Education at Tibet's Mindröling Monastery. New York: Columbia University Press.

Townsend, Dominique. 2021b. "Feeling the Way to Revelation: Patterns of Doubt and Persuasion in Tibetan Buddhist Autobiographical Treasure Narratives." Numen 68(5-6):513-539. Dor:10.1163/15685276-12341638.

Turek, Magdalena Maria. 2017. "The White Cotton Robe: Charisma and Clothes in Tibetan Buddhism Today." Religion and Society 8(1): 173-188. Dor:10.3167/ arrs.2017.080111.

Williams-Oerberg, Elizabeth. 2021. "Buddhist Ritual as 'Connectionwork': Aesthetics and Technologies of Mediating Religious Belonging." Numen 68(5-6): 488-512. DOI:10.1163/15685276-12341637. 